\title{
Detection and criterion change associated with different test contexts in recognition memory
}

\author{
L. R. ALLEN' ${ }^{1}$ AND R. F. GARTON2 \\ UNIVERSITY OF MELBOURNE
}

Three groups of physics Ss and three groups of arts Ss viewed 20 physics words ( $P W_{S}$ ) and 20 common words (CWs) in a randomly ordered inspection sequence. Ss were then assigncd to one of three recognition test conditions where the inspection items were embedded in different sequences of 120 additional words $60 \mathrm{PWs}+60 \mathrm{CWs} ; 100 \mathrm{PWs}+20 \mathrm{CWs}$, $20 \mathrm{PW}+100 \mathrm{CWs}$ ). Signal-detection and Luce analyses examined the effects of the different test contexts on Ss' true sensitivity and response bias. While all Ss found detection of $P W s$ easier than $C W s$, these judgments varied according to the properties of the recognition sequences. This latter finding was interpreted as indicating that Ss adopted a conservative and probabilistic strategy for the recognition task as a whole rather than utilizing different strategies for $P W_{s}$ and the $C W s$ where these would result in superior overall performance.

Several studies (Murdock, 1965, 1966; Parks, 1966) have indicated that various assumptions and parameters of Signal Detection Theory (TSD) (Green \& Swets, 1966: Swets, Tanner, \& Birdsall, 1961) may readily be applied to the phenomena of recognition memory. In a recent experiment Donaldson and Murdock (1968) have employed the TSD model in examining Ss' yes-no response decisions according to whether or not a recognition-test item had previously appeared in an inspection sequence. The Luce two-choice model (Luce, 1959, 1963), which has been applied to visual recognition and detection tasks (e.g., Munsinger \& Gummerman, 1968), would also appear to be a logical choice for examining data generated in a yes-no recognition memory task. Both the Luce and the TSD approaches are fundamentally concerned with separating a S's true sensitivity to a set of stimuli from the influence of various task conditions which bias his yes-no responses.

Two recent studies (Schulman, 1967; Allen \& Garton, 1968), applying a TSD analysis to verbal recognition data, have indicated that Ss are able to discriminate more easily old (signal) from new (noise) items in a recognition sequence if they are words of low frequency count as opposed to common words. While this suggests that differences in sensitivity to particular items within a word-recognition task may be manipulated by varying the characteristics of word items, it is not at all clear whether such properties influence bias parameters as both the inspection sequences and recognition test series contained an equal proportion of rare and common words.

This present study examines S's yes-no detection responses for three variations in the composition of recognition test items using two classes of stimuli-physics words (PW), which are rare in general publications, and common words (CW). An inspection sequence viewed by all Ss, contained an equal proportion of $\mathrm{PW}$ and $\mathrm{CW}$ items (signals). Three different recognition series (Lists $A, B$, and $C$ ) contained all inspection words together with varying proportions of $\mathrm{PW}$ and $\mathrm{CW}$ noise items. Thus for the recognition task as a whole the signal-to-noise ratio is 1 to 3 while $\mathrm{PW}$ and $\mathrm{CW}$ signal-to-noise ratios vary within the recognition lists as shown in Table 1 .

As can be seen from Table 1, it would be predicted that Ss may vary response criterion (the bias measure) where differences in signa-to-noise ratios are indicated. Since this
Table 1

Proportion of Signal to Noise Items (All Words, PWs, and CWs) Contained in Lists $A, B$, and $C$

\begin{tabular}{lcrr}
\hline List & All words & PWs & CWs \\
\hline A & .33 & .33 & .33 \\
B & .33 & 20 & 1.00 \\
C & .33 & 1.00 & 20 \\
\hline
\end{tabular}

measure is independent of sensitivity, the expectation from previous findings (Allen \& Garton, 1968; Garton \& Allen, in press) would be that Ss' true detection will always be higher for PWs than for CWs. The present study is designed to test these predictions. Both physics and arts S groups are included in the design since it could be contended that data obtained from either group alone may be confounded by the Ss' degree of familiarity with the meaning of PWs. For it may be assumed that arts Ss will be familiar with the CWs only, whereas the physics Ss will be familiar with all the words used in the study. Thus any effect common to both populations will be due to the variation in the proportions of the two different word-groups used rather than to the intrinsic unfamiliarity of the PWs for arts Ss. Further, the study will examine whether the Subject by Recognition conditions will yield consistent patterns of sensitivity and bias estimates according to both TSD and Luce analyses in a yes-no word-recognition task.

\section{Subjects}

\section{METHOD}

The Ss were 96 paid male undergraduate and postgraduate students, 48 having completed at least two years of an honors course in physics and 48 arts Ss having little, if any, high school science training.

\section{Materials}

The test stimuli were 120 physics words (PW) and 120 common words (CW). The selection of these items is described elsewhere (Garton \& Allen, in press). Briefly, the PWs were chosen in order to be very familiar to advanced-level physics Ss while having minimal familiarity for arts Ss. A CW [having a Thorndike-Lorge (1944) rating of 30 or more] was. paired with each PW on the basis of initial letter and word length.

The inspection sequence contained $20 \mathrm{PWs}$ and their 20 paired CWs, the order of presentation of these 40 items being randomly determined.

Three different recognition lists (A, B, and C) contained PWs and CWs in the proportions $1: 1,3: 1$, and $1: 3$, respectively. Thus, the composition of these lists was as follows:

List $\mathrm{A}-80 \mathrm{PWs}$ and $80 \mathrm{CWs}$.

List $B-120$ PWs and $40 \mathrm{CWs}$.

List $\mathrm{C}-40 \mathrm{PWs}$ and $120 \mathrm{CWs}$.

Each list contained the 40 inspection items-together with the required number of additional $\mathrm{PW}$ and $\mathrm{CW}$ items selected from the remaining stimulus items. The recognition-list items were randomly allocated to list positions with the following constraints: (a) each of the 40 inspection items occupied the same serial position in each of the three lists, and (b) the 
Table 2

TSD ( $d$ ' and Beta) and Luce (Alpha and v) Sensitivity and Bias Parameters

\begin{tabular}{|c|c|c|c|c|c|c|c|}
\hline \multirow[t]{2}{*}{ List } & \multirow{2}{*}{$\begin{array}{l}\text { Para- } \\
\text { meter }\end{array}$} & \multicolumn{2}{|c|}{ PWs } & \multicolumn{2}{|c|}{$\mathrm{CWs}$} & \multicolumn{2}{|c|}{ TWs } \\
\hline & & Phys Ss & Arts Ss & Phys Ss & Arts Ss. & Phys Ss & Arts Ss \\
\hline A & $\begin{array}{c}d^{\prime} \\
\text { beta } \\
\text { alpha } \\
\mathbf{v}\end{array}$ & $\begin{array}{r}1.84 \\
.81 \\
4.62 \\
.82\end{array}$ & $\begin{array}{r}1.56 \\
.81 \\
3.56 \\
.80\end{array}$ & $\begin{array}{l}1.27 \\
1.05 \\
2.82 \\
1.07\end{array}$ & $\begin{array}{r}.85 \\
.97 \\
1.99 \\
.93\end{array}$ & $\begin{array}{r}1.61 \\
.95 \\
3.55 \\
.96\end{array}$ & $\begin{array}{r}1.20 \\
.91 \\
2.60 \\
.88\end{array}$ \\
\hline B & $\begin{array}{c}d^{\prime} \\
\text { bets } \\
\text { alpha } \\
\mathbf{v}\end{array}$ & $\begin{array}{r}1.69 \\
.89 \\
3.96 \\
.88\end{array}$ & $\begin{array}{r}1.08 \\
.78 \\
2.39 \\
.69\end{array}$ & $\begin{array}{r}.66 \\
1.00 \\
1.70 \\
1.01\end{array}$ & $\begin{array}{r}.77 \\
1.02 \\
1.88 \\
1.05\end{array}$ & $\begin{array}{l}1.27 \\
1.06 \\
2.81 \\
1.08\end{array}$ & $\begin{array}{r}.94 \\
.89 \\
2.11 \\
.81\end{array}$ \\
\hline C & $\begin{array}{l}d^{\prime} \\
\text { beta } \\
\text { alpha } \\
v\end{array}$ & $\begin{array}{r}1.82 \\
.62 \\
4.43 \\
.63\end{array}$ & $\begin{array}{r}1.22 \\
.69 \\
2.71 \\
.60 \\
\end{array}$ & $\begin{array}{r}.82 \\
1.29 \\
1.95 \\
1.67 \\
\end{array}$ & $\begin{array}{r}.72 \\
1.00 \\
1.71 \\
.94 \\
\end{array}$ & $\begin{array}{l}1.26 \\
1.10 \\
2.74 \\
1.14 \\
\end{array}$ & $\begin{array}{r}.92 \\
.87 \\
2.10 \\
.77 \\
\end{array}$ \\
\hline
\end{tabular}

proportion of $\mathrm{PW}$ to $\mathrm{CW}$ items within each of the four quarters of a recognition series remained constant (that is, 20:20 for List A, 30:10 for List B, and 10:30 for List C). This second restriction was imposed in order to prevent spurious results as a consequence of Ss' adopting changes in criterion in different stages of the recognition task (Donaldson \& Murdock, 1968).

\section{Procedure}

The Ss were tested in small groups. Prior to the presentation of the inspection items, Ss were instructed to attempt to remember the words which would appear on a screen. Each of the $\mathbf{4 0}$ inspection items was presented for 2 sec using a Kodak Carousal automatic projector (Model 55OR) with a 0.5 -sec interitem presentation interval. Eighteen physics Ss and 18 arts Ss were assigned to each of the three recognition-list conditions. There was a $2-\mathrm{min}$ interval between the completion of the inspection sequence and the start of the recognition task. The Ss were instructed that they would be presented with a list of words and that they must record a yesno decision in a box beside each word according to whether or not a word was judged to have previously appeared in the inspection sequence.

\section{RESULTS}

The proportion of inspection-list words correctly identified as present (HR) and the proportion of false-positives (FAR) were obtained. The HR and FAR measures were also determined for PWs and CWs separately. The TSD estimates, $d$ ' and beta, were obtained from tables constructed by Freeman (1964). The corresponding Luce estimates, alpha and $v$, were calculated using the formulae derived from Shipley (1965, p. 280) and Broadbent (1965, pp. 153-154):

$$
\text { and } \begin{aligned}
\alpha^{2} & =[H R(1-\text { FAR })] /[(1-H R)(F A R)] \\
v^{2} & =[(1-H R)(1-\text { FAR })] /[(H R)(F A R)]
\end{aligned}
$$

The TSD and Luce parameters for physics and arts Ss are shown in Table 2 as a function of the particular recognition list employed.

An inspection of Table 2 will show that in all cases a direct correspondence exists between $d^{\prime}$ and alpha and between beta and v. Thus both TSD and Luce analyses have revealed the same pattern of relationships between sensitivity and bias within the whole set of word-recognition data. Consequently, in the following exposition the TSD measures only will be used to clarify the argument, although the Luce measures would be equally acceptable.

The major analysis is concerned with the effects of varying the composition of recognition-list items. In terms of the physics Ss' overall performance for the total 160 recognitionlist items, the List $\mathbf{A}$ condition resulted in best discrimination of old from new items ( $d^{\prime}$ of 1.61 , Table 2) while there was no significant difference in discrimination between Lists $B$ and $C$ (1.27 and 1.26). Similarly for arts Ss, List A discrimination was superior (1.20) to that of either List B or List C $(.94$ and .92). Table 2 clearly shows that PWs were generally better recognized than CWs for both groups of Ss. Moreover, the $d^{\prime}$ for each PW comparison is higher for physics Ss than for arts Ss. From Fig. 1 where HRs and FARs are plotted, it is apparent that the superiority of physics Ss on PWs is not so much the result of higher HRs for physics Ss but rather due to arts Ss having higher FARs on all lists. This is particularly

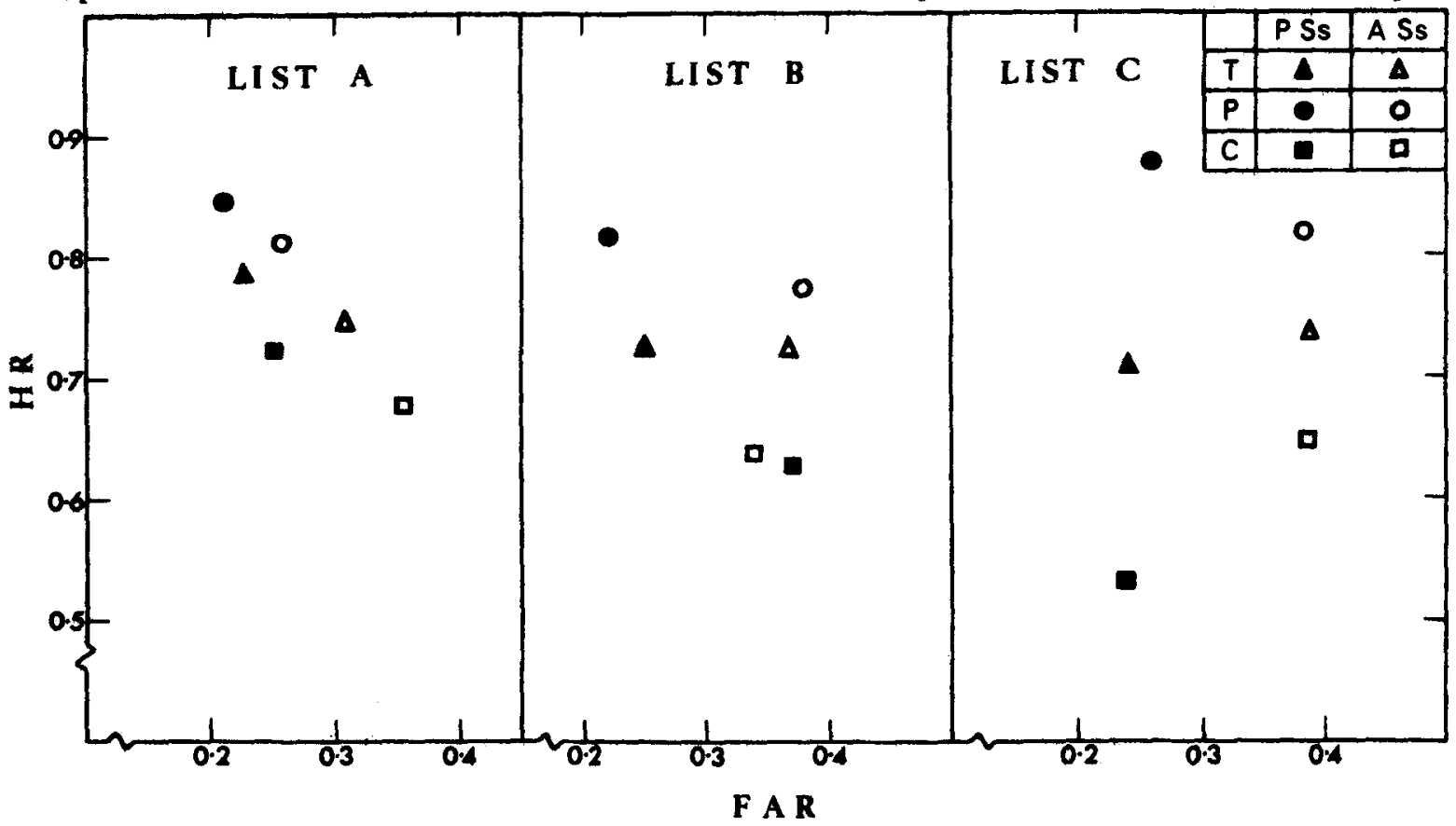

Fis. 1. Hit rete plotted apinat fabe-alarm rate for physics and arts Ss on the three recognition lists, A, B, and C, where T refers to all words, $C$ to common words, and $P$ to physies words. 


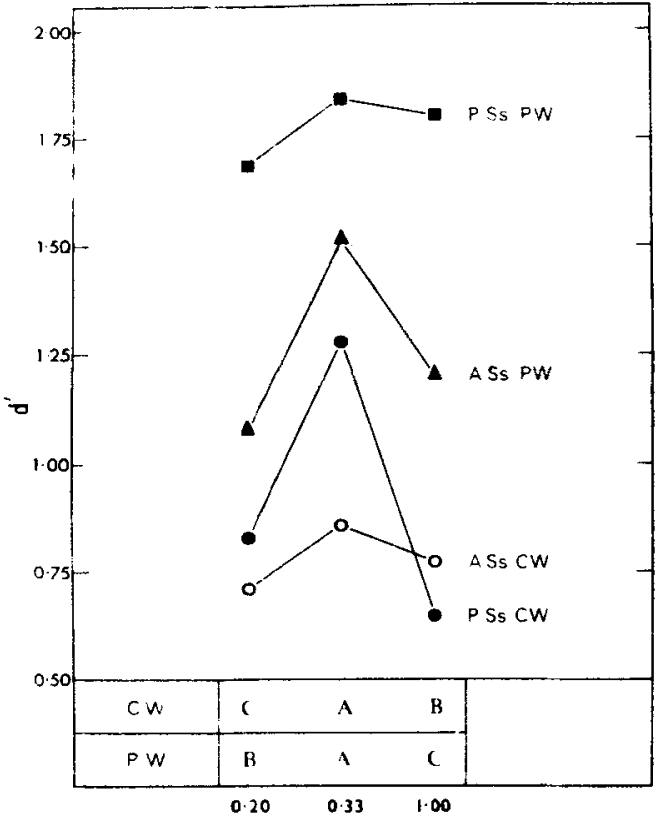

Fig. 2. Proportion of signal to noise items where $A, B$, and $C$ refer to the three test lists.

noticeable in List B where arts Ss have a FAR of approximately 4 compared with .2 for physics Ss. Now. should a $S$ be uncertain whether a particular List B PW were old or new, the logical response would be "no" (new) since the proportion of old to new PWS is $3 \cdot 1$. However, both $\mathrm{S}$ groups tend to respond "yes" (old) when unsure (betas of .78 and .89 in Table 2). This phenomenon does not occur where the proportion of old to new CSs is 31 withm List C. Here, arts Ss show no bias for "yes" or "no" (1.00) while physics Ss show a bias to respond "no" $(1.29)$ as might be expected if a logical approach were adopted. The only other finding reflecting luglcal bias tendencies occurred for CWs on List B where the proportron of old to new $C W$ items is $1: 1$ (betas of 1.02 and 1.00)

The $\mathrm{d}^{\prime}$ measures for PWs and CWs are presented in Fig. 2 as a function of the proportion of signal to noise for each recognition condition. It can be seen that for both PWs and CWs, better recognation occurred for both physics and arts Ss on List A where the signal to noise proportion is identical $(.33)$ for both word classifications.

\section{DISCUSSION}

One of the more general questions raised in this study concerned the conditions affecting the superior detection of rare words compared with common words when the proportions of these items were varied in a recognition-test sequence. It seems clear that considerable flexibility in such characteristics of the context or noise items in a recognition test has not vitiated the suggestion that Ss were better able to detect old from new items if they were PWs rather than CWs (Allen \& Garton, 1968). For each of the possible paired comparisons of $\mathrm{PW}$ and $\mathrm{CW}$ detections in Table 2, both physics and arts Ss displayed superior PW detectability.

The demonstrated relationship between sensitivity and bias for the three recognition conditions, however, is complex. Of particular interest is the apparently counterintuitive result which appears contrary to the findings of Markowitz and Swets $(1967)$ that the higher the proportion of signal-to-noise items, the higher would be the value of $d^{\prime}$. Stated in terms of this research, it would be expected that the detection of 20 out of 40 items would be superior to detecting 20 out of 80 items provided that the items were of comparable difficulty. However, an inspection of Fig. 2 will show that this is not the case. While $S$ s found the detection of 20 items from 120 harder than detecting 20 out of 80 , the detection of 20 out of 40 items proved to be more difficult than the detection of 20 out of 80 . That this was not due to chance, or an artifact of a particular recognition list, is apparent when it is considered that this trend was evident for both physics and arts Ss and also for both word groups. Nor is this finding a function of differing biases being adopted for PWs or for CWs considered separately. For example, bias estimates were similar for the greatest $C W$ sensitivity difference in Fig. 2 (physics $S$ s responding to CWs on Lists $A$ and $B$ have betas of 1.05 and 1.00); they were also similar for the arts Ss PW difference on Lists $A$ and $C$ (betas of .81 and .69).

One suggestion which may clarify these findings is that a $S$ may set his criterion such that he will probably designate as cases of signal a proportion of instances approximately equal to the a priori probability of signal occurrence (Creelman \& Donaldson, in press). Table 1 has indicated a constant signal-to-noise ratio for the three recognition conditions while PW and CW ratios were varied within each recognition sequence. It may be suspected that such manipulations of recognition-list items would result in Ss' adopting a different yes-no criterion for PWs and for CWs on Lists $B$ and $C$. However, it would appear that Ss have in fact responded to CWs on List B and to PWs on List C with a similar task bias as their overall bias on these lists. Should this be so, then a $S$ reduces his hit rate, and consequently $d^{\prime}$, considerably; for if his yes-no responses are approximately in the proportion 40.120 or $1: 3$, he must miss a lot of old words as the true ratio is $1: 1$. It seems incredible, yet nevertheless evident from the right hand side of Fig. 2, that Ss were oblivious of the true probability of occurrence of CWs on List B and PWs on List C. It would seem that the only likely conclusion would be that the S acts as an "intuitive statistician," as Brunswik (1956) has proposed, only for the molar or complete task. That is, the $S$ is unable to adopt two different strategies during a single recognition task when these would be required in order to maximize success for particular subtask conditions.

One may conclude that man is a conservative processor of information. for he utilizes a probabilistic sampling strategy, as Peterson, DuCharme and Edwards (1968) have shown.

\section{REFERENCES}

ALLEN, L. R.. \& GARTON, R. F. The influence of word-knowledge on the word-frequency effect in recognition memory. Psychonomic Science, $1968,10,401-402$.

BROADBENT, D. E. A reformulation of the Yerkes-Dodson Law. British Joumal of Mathematical \& Statistical Psychology, 1965, 18, 145-157.

BRUNSWIK, E. Perception and the representative design of psychological experiments. (2nd ed.) Los Angeles: University of California Press, 1956.

CREELMAN, C. D., \& DONALDSON, W. ROC curves for discrimination of linear extent. Journal of Experimental Psychology, in press.

DONALDSON, W., \& MURDOCK, B. B. Criterion changes in continuous recognition memory. Journal of Experimental Psychology, 1968, 76, 325-329.

FREEMAN, P. R. Table of d' and beta. Technical Report No. 529/64, Applied Psychology Unit, Cambridge, England, 1964.

GARTON, R. F., \& ALLEN, L. R. Familiarity and word recognition. Quarterly Journal of Experimental Psychology, in press.

GREEN, D. M., \& SWETS, J. A. Signal detection theory and psychophysics. New York: Wiley, 1966

LUCE, R. D. Individual choice behavior. New York: Wiley, 1959.

LUCE, R. D. Detection and recognition. In R. D. Luce, R. R. Bush, and F. Mosteller (Eds.), Handbook of mathematical psychology. Vol. 1. New York: Wiley, 1963.

MARKOWITZ, J., \& SWETS, J. A. Factors affecting the slope of empirical ROC curves: Comparison of binary and rating responses. Perception \& Psychophysics, 1967, 2, 91-100.

MUNSINGER, H., \& GUMMERMAN, K. Simultaneous visual detection and recognition. Perception \& Psychophysics, 1968, 3, 383-386. 
MURDOCK, B. B. Signal-detection theory and short-term memory. Journal of Experimental Psychology, 1965, 70, 443-447.

MURDOCK, B. B. The criterion problem in short-term memory. Journal of Experimental Psychology, 1966, 72, 317-324.

PARKS, T. E. Signal-detectability theory of recognition-memory performance. Psychological Review, 1966, 73, 44-58.

PETERSON, C. R., DuCHARME, W. M., \& EDWARDS, W. Sampling distributions and probability revisions, Journal of Experimental Psychology, 1968, 76, 236-243.

SCHULMAN, A. I. Word length and rarity in recognition memory. Psychonomic Science, 1967, 9, 21 1-212.

SHIPLEY, E. F. Detection and recognition: Experiments and choice models. Journal of Mathematical Psychology, 1965, 2, 177-311.
SWETS, J. A., TANNER, W. P., \& BIRDSALL, T, G. Decision processes in perception. Psychological Review; 1961, 68, 301-340.

THORNDIKE, E. L., \& LORGE, I. The teacher's word book of 30,000 words. New York: Columbia University Press, 1944.

\section{NOTES}

1. Present Address: Department of Psychology, University of Melbourne, Parkville, 3052, Victoria, Australia.

2. Both authors contributed equally to this work, the order of authorship being determined on a chance basis.

(Accepted for publication January 6, 1969.) 